\title{
A Study on the Relationship between the Poverty Level and the Financial Agglomeration in the Poverty County of Guizhou Province*
}

\author{
Hongmei Zhang ${ }^{1,2,3}$, Ning Zhang ${ }^{1,2,3}$ \\ 1 Guizhou University of Finance and Economics, Institute of Finance \\ 2Guizhou Institution for Technology Innovation \& Entrepreneurship Investment \\ 3Guizhou Institute of Urban Economics and Development Guiyang Guizhou
}

550025, China

\section{贵州省黔西南州贫困县贫困度与金融集聚关系 研究}

\author{
张红梅 ${ }^{1,2,3}$, 张宁 ${ }^{1,2,3}$
}

1 贵州财经大学金融学院; 2. 贵州科技创新创业投资研究院; 3. 贵州城镇经济与发展研究院 贵州贵阳 550025

\begin{abstract}
Poverty is one of the major obstacles to economic development and social stability. Finance plays an increasingly important role in the economic field of a country. Is there a relationship between the degree of poverty reduction and the level of financial development? Domestic and foreign scholars have not yet reached a consensus conclusion.
\end{abstract}

\footnotetext{
*资助项目: 本文由贵州省科技计划项 目黔科合基础 [2016]1534-4 号资助

(项目名称：贵州新型城镇化金融支 持效率研究）; 贵州财经大学 2018 年 度在校学生科研资助项目 (项目名 称：贵州省黔西南州贫困县生态扶贫 的金融支持研究）。

作者简介：张红梅，教授、硕士生导 师, 任职于贵州财经大学金融学院, 研究方向: 金融与区域发展、贫困地 区金融。Email：zhm1035@qq. com。张 宁, 男, 贵州财经大学金融学院研究 生。研究方向：金融与区域发展。 Emai1: 809089169@qq. com。
}

Therefore, this paper uses the data of 2017 in seven key poverty-stricken counties in southwestern Guizhou Province, using principal component analysis, cluster analysis and entropy method, to empirically analyze the relationship between the poverty level and financial development level in poverty counties. The empirical results show that the degree of poverty is related to financial development, that is, the higher the level of financial agglomeration, the lower the degree of poverty; the lower the level of financial agglomeration, the higher the degree of poverty. Therefore, a correct understanding of the role of financial agglomeration in poverty alleviation will help promote Guizhou Province to reduce poverty through financial reforms and provide an important reference for the formulation of relevant policies.

Keywords: precise poverty alleviation; poverty degree; financial agglomeration level; entropy method

摘要

贫困问题是制约经济发展和影响社会稳定 
的重大障碍性因素之一。金融在一个国家 经济领域中发挥出越来越重要的作用。贫 困程度减缓与金融发展水平之间是否存在 关系? 国内外学者尚未取得一致性的结 论。因此本文采用贵州省黔西南州 7 重点 贫困县 2017 年的数据, 利用主成分分析 法、聚类分析法和熵值法, 实证分析贫困 县的贫困程度和金融发展水平两者的关 系。实证结果表明, 贫困程度与金融发展 具有相关性即金融集聚水平越高, 贫困程 度越低; 金融集聚水平越低, 贫困程度越 高。故正确认识金融集聚水平对贫困程度 减缓的作用，有利于促进贵州省通过金融 改革减少直至消除贫困, 并为相关政策的 制定提供重要的参考依据。

关键词: 精准扶贫; 贫困程度; 金融集聚 水平; 熵值法

\section{1. 引言}

十八大以来, 习总书记对扶贫工作提 出了 “精准扶贫” 的新要求, 明确要求扶 贫工作应当立足地方发展的实际情况, 因 地制宜, 因人定策, 灵活的开展个性化扶 贫工作。脱贫攻坚已经成为全面建成小康 社会的底线任务和标志性指标, 脱贫攻坚 战是十九大提出的三大攻坚战之一, 充分 彰显了新一代中央领导集体对扶贫工作的 高度重视。近几年来, 贵州省着力于探索 扶贫模式, 围绕着 “精准扶贫, 精准脱 贫” 的要求，大力实施金融扶贫、生态扶 贫等扶贫工程, 有效的发挥了各个方面在 脱贫攻坚战中的作用, 取得了一定的成 效。但是因其历史、地理位置、自然、社 会、民族和科学技术的原因, 贵州想要打 赢脱贫攻坚战, 还需要继续努力。此外, 贵州省实施的精准扶贫模式存在一定的缺 陷, 制约了扶贫有效进行。国内外专家学 者对金融发展水平对贫困程度减缓进行了 深入研究。

关于金融发展对贫困程度减缓有利方 面, Remenyi 和 Quinones(2000)对亚太地区 一些国家的案例进行分析, 研究表明获得 微型金融信贷服务的人群, 其收入可以得 到明显提 高 ${ }^{[1]}$ 。Jeanneney 和 Kpodar
(2005), 考虑金融发展和金融波动性这两方 面的影响要素, 通过计量模型分析金融发 展、金融波动与贫困减少之间的关系。他 们认为金融发展对贫困减少有直接和间接 的影响 ${ }^{[2]}$ 。段应碧( 2011)提出破解贫困农户 贷款难题, 必须培育和发展不以盈利为目 的的公益性小额信贷组织 ${ }^{[3]}$ 。

关于金融发展对贫困程度减缓不利方 面, Fowowe 和 Abidoye(2005)以私人信贷 作为衡量金融发展的指标, 检验了撒哈拉 以南非洲各国家的金融发展对贫困减少并 没有显著的影响 ${ }^{[4]}$ 。杨小玲(2009)利用我国 农村地区 1978 到 2007 年的数据, 对农村 金融发展水平对贫困减少的长短期影响进 行检验。结果表明, 从短期来看, 金融发 展水平减缓程度具有促进作用, 但效果不 够明显。长期来看, 农村金融发展结构则 能抑制贫困的减少 ${ }^{[5]}$ 。陈银娥、师文明 (2010) 利用时间序列数据分析, 研究显示 农村正规金融发展对农村贫困减少的影响 很小，而金融波动不利于农村贫困的减 少, 非正规金融发展对农村贫困减少也没 有促进作用 ${ }^{[6]}$ 。

根据以上国内外文献的研究成果, 对 于金融发展水平对贫困程度减缓存在有利 和不利两个方面, 并且国内对于金融发展 对贫困程度减缓的研究文献相对较少。而 且, 对于我国的贫困主要集中在县域, 因 此, 研究贫困县金融发展水平对贫困程度 减缓显得尤为重要。在此基础上本文选取 贵州省黔西南州贫困县作为研究对象来分 析金融发展水平对贫困程度减缓的作用。

\section{2. 黔西南州贫困县聚类分析}

\section{1 主成分分析和聚类分析概念}

统计分析方法包括主成分分析法、相 关分析法、回归分析法和时间序列分析 法, 其中主成分分析是比较常用的方法 [7][10]。主成分分析是对多变量数据进行统 计处理的一种数据线性投影方法, 即如何 把多个变量转化为少数几个综合变量, 而 这几个综合变量可以反映多个变量的信 息。其基本思想是以最优化方法缩减多维 数据的信息, 使得数据矩阵简化, 降低维 
数, 寻找几个能代表原始数据的线性组合 的主成分, 从而达到提取主要信息的目 的。

聚类分析是根据 “物以类聚” 的道 理, 对样本指标进行分类, 使得同一类中 的对象之间的相似性比与其他类的对象的 相似性更强的一种多元统计分析方法。实 施聚类分析主要是为了把相似的研究对象 归成类, 使类内对象的相似性最大化和类 间对象的差异性最大化。聚类分析法主要 包括系统聚类、 K-均值聚类 ${ }^{[8]}$ 、有序聚 类、动态聚类、分层聚类和迭代聚类等。

值得注意的是, 在聚类分析时, 指标 体系之间涵盖的相同信息较多, 分析结果 会出现误差; 而使用主成分分析可通过降 维, 减少变量之间相关信息的交叉性, 在 此基础线上进行聚类分析可使得数据更加 简约、结果更加贴近现实情况。因此本文 中将使用主成分分析法和聚类分析法结合 在一起使用, 最终得到的结果比起单独使 用聚类分析效果好。

\section{2 指标体系构建}

衡量一个地区的贫困程度的数值有很 多, 为保持指标的权威性和重要性, 本文 借鉴了刘月, 师谦友等人（2012）的研究, 通过对现有数据的笕选、整理和加工, 基 于数据的可比性、全面性和可操作性原 则, 根据 2017 年《贵州省统计年鉴》和黔 西南各县的统计公报, 选取了 6 个指标数 据构建指标体系: $\mathrm{x} 1$ 为农村居民人均纯收 入 (元) 、 $\mathrm{x} 2$ 为人均生产总值 (元)、 $\mathrm{x} 3$ 为城镇居民人均可支配收入 (元)、 $\mathrm{x} 4$ 为 固定资产投资 (万元) 、 $\mathrm{x} 5$ 为总人口 （人）、 $\mathrm{x} 6$ 为固定电话用户 (户)。

\section{3 实证分析}

\subsection{1 主成分分析}

(1) 主成分提取。进行主成分分析之前, 首先要检验所选择指标是否适合主成分分 析, 根据检验 $\mathrm{KMO}$ 的值为 0.687 , ,Bartlett 球形度检验的卡方分布值为 42.143 , 对应 的 sig 值为 0.000 , 小于 0.05 。因此测量贫 困程度的指标变量满足主成分分析的条
件, 可以做主成分分析。

采取主成分分析对所有的指标变量提 取主成分, 计算各个主成分的特征值和贡 献率可知, 提出两个主成分因子, 分别为 F1、F2。它们分别可以解释原始变量 $71.351 \%$ 和 21 。 $206 \%$

(2) 计算主成分得分。根据所提取的 2 个 主成分, 运用 spss 23 软件计算主成分载荷 矩阵。

根据主成分载荷矩阵可得到两个主成分 $\mathrm{Y} 1$ 和 Y2 的表达式如下:

$\mathrm{Y} 1=0.476 \times \mathrm{ZX} 1+0.446 \times \mathrm{ZX} 2+0.411 \times \mathrm{ZX} 3+$

$0.457 \times Z X 4+0.434 \times Z X 5-0.097 \times X 6 \quad$ (1)

$\mathrm{Y} 2=0.080 \times \mathrm{ZX} 1-0.151 \times \mathrm{ZX} 2-0.278 \times \mathrm{ZX} 3+$

$0.133 \times \mathrm{ZX} 4+0.38 \times \mathrm{ZX} 5+0.856 \times \mathrm{ZX} 6$

其中 ZX1 ZX6 是原始变量的标准值, 而不 是原始值。

(3) 综合评价。

通过主成分分析, 将 6 个指标变量降 为 2 个主成分 $Y 1 、 Y 2$, 如表 1 所示。通常 综合评价得分都是采用回归方法估计出因 子得分, 以及个因子的方差贡献率作为权 重进行汇总。但是本文对权重进行了归一 化处理, 则 $W 1$ 、 W2 分别为 $71.351 / 92.557$ 和 21.206/92.557, 则

$\mathrm{Y}=(71.351 \times \mathrm{Y} 1+21.206 \times \mathrm{Y} 2) / 92.557$

表1 黔西南地区7个贫困县综合得分、排序

\begin{tabular}{|c|c|c|c|c|}
\hline 地区 & $Y 1$ 得分 & $Y 2$ 得分 & $Y$ & 排序 \\
\hline 兴仁县 & 2.96 & 0.5 & 2.4 & 1 \\
\hline 贞丰县 & 1.78 & -1.01 & 1.14 & 2 \\
\hline 安龙县 & 0.93 & 1.6 & 1.08 & 3 \\
\hline 普安县 & -0.02 & -0.87 & -0.22 & 4 \\
\hline 晴隆县 & -0.67 & -0.72 & -0.68 & 5 \\
\hline 望谟县 & -2.69 & 1.35 & -1.77 & 6 \\
\hline 册亭县 & -2.28 & -0.85 & -1.95 & 7 \\
\hline
\end{tabular}

\subsection{2 聚类分析}

为了进一步明确各个贫困县的发展情 况, 本文进行聚类分析所采用的是系统聚 类分析, 聚类方法为组间连接, 测量区间 使用平方欧式距离。本文运用 spss（23.0） 中的聚类分析程序模块, 以上述的主成分 分析得到的 $Y 1$ 得分、 $Y 2$ 得分和 $Y$ 综合得 
分的结果作为聚类分析的变量, 对黔西南 7 个贫困县进行聚类分析, 得到 7 个贫困县 的聚类分析的谱系图和聚类结果（表 2)， 并可用图 1 的聚类谱系图表之。

\begin{tabular}{|c|c|c|c|}
\hline \multicolumn{4}{|c|}{ 表2 聚类结果 } \\
\hline \multirow{6}{*}{$\begin{array}{l}\text { 地区 } \\
\text { 聚类 }\end{array}$} & 兴仁县 & 贞丰县 & 安龙县 \\
\hline & 1 & 1 & 1 \\
\hline & 普安县 & \multicolumn{2}{|r|}{ 晴隆县 } \\
\hline & 2 & \multicolumn{2}{|r|}{2} \\
\hline & 望谟县 & \multicolumn{2}{|r|}{ 册亨县 } \\
\hline & 3 & \multicolumn{2}{|r|}{3} \\
\hline
\end{tabular}

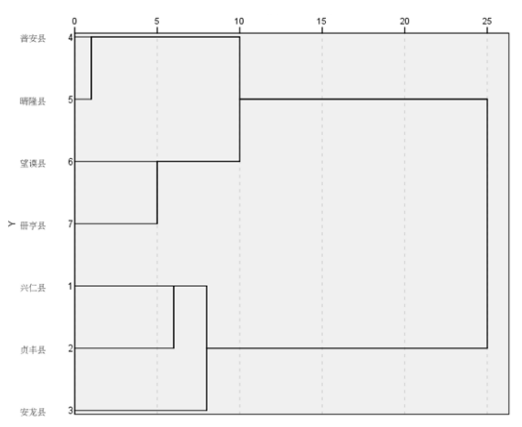

图1 聚类谱系图

综上, 结合主成分分析和聚类分析 （表 1 、表 2 和图 1) 结果, 将黔西南州贫 困县大致划分为以下三类:

第一类是兴仁县、贞丰县和安龙县。 三个县的综合得分为 $2.4 、 1.14 、 1.08$, 表 明这三个县经济和社会发展水平相对较 好, 综合实力较强。现实生活中, 兴仁县 地处黔西南州中部, 是黔、滇、桂三省(区) 结合部的中心县; 贞丰县是红七军、红八 军长期活动过的革命老区, 旅游发展较 好; 安龙县地处黔桂两省(区)结合部, 一直 是南北盘江流域重要经济文化中心。基上 述分析, 可以认为三个县为贫困县中的发 展相对成熟型。

第二类是普安县和晴隆县。两个县的 综合得分为 $-0.22 、-0.68$, 表明这两个县的 发展水平较弱。普安县位于贵州省西南部 乌蒙山区; 晴隆县位于黔西南州西北角, 是典型的喀斯特地貌, 山高谷深。由于地 形地貌的原因致使发展速度较慢, 可以认 为这两个县为贫困县中的发展成长型。
第三类是望谟县和册亨县。两个县的 综合得分为-1.77、-1.95。两个县在黔西南 综合实力排名为 6 和 7 名, 在贵州省 88 个 县市区里的经济实力排名为 73 和 82 名, 无论是在地方还是在全省发展水平都是相 对落后。可以认为这两个县为贫困县中的 发展落后型。

\section{3. 摘值法分析黔西南各县的金融金融集聚 水平}

\section{1 金融集聚水平测度}

\subsection{1 熵值法}

熵代表定性概念的可度量度, 定性概念 的不确定性随着熵越大而变大 ${ }^{[9]}$ 。熵原本 是物理中热力学概念, 后来发展成为信息 论的熵值法理论, 在指标赋权方面应用比 较广泛。在信息论中, 熵是对不确定性的 的一种度量。信息量越大, 不确定性越 小, 熵就越小; 信息量越小, 不确定性越 大, 熵就越大。权重是指标重要性的量化 表示, 可根据目标的重要性赋予不同的 值, 且所有指标权重之和应等于 1 。

\subsection{2 熵值法计算步骤}

(1) 原始数据的无量纲化。

为了消除指定指标因为单位不统一和 数量级的不同, 在进行各项指标的赋权之 前, 需要对指定的指标进行归一化处理, 即无量纲化处理。若数据中有负数, 就需 要对数据进行非负化处理, 同时为了避免 熵值法求对数是的无意义情况的出现, 需 要对数据进行平移:

对大者为优的指标而言:

$$
X_{i j}^{\prime}=\frac{X_{i j}-\min X_{i j}}{\max X_{i j}-\min X_{i j}}+1
$$

$i=1,2 \ldots \ldots n, j=1,2 \ldots \ldots n$

对于小者为优的指标而言:

$$
X_{i j}=\frac{\max X_{i j}-X_{i j}}{\max X_{i j}-\min X_{i j}}+1
$$

$i=1,2 \ldots \ldots n, j=1,2 \ldots \ldots n$

(2) 度量化指标。 
计算第 $j$ 项指标下, 第 $i$ 个县所占该指 标的比重。

$$
P_{i j}=\frac{A_{i j}}{\sum_{i=1}^{n} A_{i j}}, \quad i=1,2 \ldots \ldots . n, j=1,2 \ldots \ldots . m
$$

( $n$ 为贫困县个数, $m$ 为指标个数)

(3) 计算第 $j$ 项指标的熵值。

$$
E_{j}=-k \sum_{i=1}^{m} A_{i j} \ln \left(A_{i j}\right)
$$

其中 $E_{j}$ 表示为所有样本对指标的贡献 总量, 常数 $k=1 / l n(m)$, 这样的话能使得 $0 \leqq E_{j} \leqq 1$, 确保 $E_{j}$ 最大值为 1 。由上式我们 看出, 当各个样本的贡献度一致时, $E_{j}$ 接 近于 1 。

(4) 计算第 $j$ 项指标的差异系数即 $D_{j}=1$ $E_{j}$ 。 $D_{j}$ 为第 $j$ 个指标下个样本贡献度的一致 性程度。

(5) 求权重。 $W_{j}=\frac{D_{j}}{\sum_{j=1}^{m} D_{j}}, j=1,2 \ldots \ldots m$

(6) 计算第 $i$ 个县的金融集聚程度。

$$
S_{i}=\sum_{j=1}^{m} W_{j} * P_{i j}, i=1,2 \ldots \ldots n
$$

\section{2 构建金融集聚水平测度指标体系}

\subsection{1 金融集聚内涵}

金融集聚是指金融行业中的一些部门 或者企业等具有总部功能的机构在某一地 区形成集中的趋势, 并与其他国际性机构 之间存在密切往来联系的一种产业空间结 构。当前金融集聚的模式主要存在两种情 况: 一种是以市场作为主导, 另一种是以 政府作为主导。

\subsection{2 构建指标体系}

对于金融集聚水平的测度, 本文借鉴 丁艺、李树丞、李林 (2009), 豆晓利 (2012), 李静、白江 (2014) 等研究。 选取指标包括金融规模、金融基础和经济
规模三个方面（表 3）。数据来源 2017 年

\begin{tabular}{|c|c|c|}
\hline 目标 & $\begin{array}{c}\text { 一级指 } \\
\text { 标 }\end{array}$ & 二级指标 \\
\hline 金融集聚 X & $\begin{array}{l}\text { 金融规 } \\
\text { 模 X1 } \\
\text { 金融基 } \\
\text { 础 X2 } \\
\\
\text { 经济规 } \\
\text { 模 X3 }\end{array}$ & 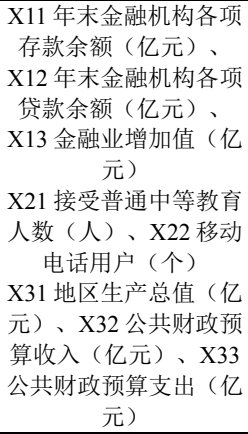 \\
\hline
\end{tabular}
《贵州省统计年鉴》和黔西南统计公报。

表3 指标体系

\section{3 实证分析}

采用熵值法对各个指标进行赋权, 本 文所采用的指标均为大者为优, 将原始数 据进行无量纲化, 然后计算出各项指标的 熵值依次为 $0.0165 、 0.0155 、 0.0143$ 、 $0.0138 、 0.0148 、 0.0112 、 0.0101 、 0.0146$, 据此计算各项的权重依次为 0.1489 、 $0.1399 、 0.1291 、 0.1245 、 0.1336 、 0.1011$ 、 $0.0912 、 0.1318$ 。

熵值法能够深刻反映出指标信息熵值 的效用价值, 从而确定权重这种思想, 作 为一种客观赋权法, 由它得出的指标权重 值比主观赋权具有较高的可信度和精确 度。在此基础上, 需要进行金融集聚水平 测度, 通过指标熵权结果和无量纲化后的 数据, 得到黔西南各个县的金融水平的测 度结果, 测度值越高, 金融集聚水平越 高。由表 4 不难看出, 黔西南 7 个贫困县 金融金融集聚水平差异十分明显, 最高的

表 4 金融集聚水平测度值

\begin{tabular}{|c|c|c|}
\hline 地区 & 测度值 & 排序 \\
\hline 兴仁县 & 0.201273 & 1 \\
\hline 安龙县 & 0.168237 & 2 \\
\hline 贞丰县 & 0.158313 & 3 \\
\hline 普安县 & 0.132265 & 4 \\
\hline 晴隆县 & 0.117434 & 5 \\
\hline 望谟县 & 0.116846 & 6 \\
\hline 册亨县 & 0.105631 & 7 \\
\hline
\end{tabular}


是兴仁县, 金融集聚水平综合得分 0.201273 , 相当于册亨县的 1.9 倍。

\section{4. 政策建议}

综合黔西南州贫困县聚类分析和金融 金融集聚水平测度, 黔西南 7 个贫困县分 为三类分别为发展相对成熟型、发展成长 型和发展落后型; 金融集聚水平测度发现 兴仁县、安龙县和贞丰县位列前三名, 普 安县和晴隆县位于四五名, 望谟县和册亨 县为最后两名。由此可知, 贫困县发展情 况受到金融集聚的影响。这主要是因为金 融体系自身发展程度会直接减少贫困和金 融发展通过经济增长引起收入分配变化间 接减少贫困导致的。通过分析发现, 减少 贫困程度的金融支持需要从以下三个方面 进行:

（1）政府和金融市场要明确自己的职 能, 构建完善的金融扶贫体系。在金融扶 贫的过程中, 政府要发挥主导、引领的作 用, 要负责国家扶贫政策的实施, 充分了 解本地区的贫困情况, 同时要制定适应本 地区的金融扶贫政策; 金融市场要做好资 源配置的功能, 从各个层面引导金融发 展, 构建有限的金融发展机制, 提高不同 农民对金融服务的需求，提供完善的金融 服务环境。

（2）优化金融扶贫体系环境。金融机 构要积极构建和改善信用环境建立健全贷 款风险、企业和个人信用管理体制, 加强 对守信用的企业和个人的贷款力度, 从而 达到增强县域内的信用意识; 农村金融扶 贫部门较多, 想要有效的评估各个金融部 门的效率, 提高金融市场资源配置的功 效, 需要制定科学有效的精准扶贫体系、 优惠政策。

（3）提升贫困和特困群众脱贫力度。 由于贫困地区自然环境恶劣和基础设施建 设不足, 想要实现长期有效的可持续发 展, 不仅仅要靠金融机构贷款扶持, 引进 投资, 发展中小型企业, 还要依赖于金融 机构自身发展, 为贫困地区的脱贫提供动 力。同时, 也要大力发展互联网的强大功 能, 利用互联网建立有效的传导机制, 从
而让贫困县的金融机构发展获得更多的机 会和更大的可能性。

\section{参考文献}

[1] J.Remenyi,Q. Benjamin . Microfinance and Poverty Alleviation: Case Studies from Asia and the Pacific, New York: Pinter Publishers, 2000.

[2] S. Jeanneney,K. Kpodar. Financial Development, Financial Instability and Povery, CSAE Working Paper Series, 2005.

[3] 段应碧.发展公益性小额信贷组织, 破 解贫困农户贷款难题 $[\mathrm{J}]$. 农业经济 问题, 2011，(1):4-6.

[4] B. Fowowe,B. Abidoye. A quantitative Assessment of the Effect of Financial Development on Poverty in African Countries,Department of Economics, 1-19, 2005.

[5] 杨小玲.中国农村金融发展与贫困减少 的实证研究 [J]. 金融教学与研究, 2009, (6) : 12-16

[6] 陈银娥, 师文明.中国农村金融发展与 贫困减少的经验研究 $[\mathrm{J}]$.中国地质大 学学报(社会科学版), 2010,10(6):100105.

[7] XianfuCheng,HonghuSun,ZhangYuan,Gu anglaiXu .Flood Disaster Risk Assessment and Spatial Distribution Characteristics along the Yangtze River in Anhui Province,Journal of Risk Analysis and Crisis Response, 2014, 4 (4) : 238-242.

[8] Mu Zhang ,ZongfangZhou.A Credit Rating Model for Enterprises Based on Projection Pursuit and K-Means Clustering Algorithm,Journal of Risk Analysis and Crisis Response, 2012, 2 (2) : 131-138.

[9] Ying He.Assessment Research of Bijie Drought Risk Based On Cloud Model,Journal of Risk Analysis and Crisis Response, 2013, 3 (4) : 192200.

[10] Hong-Mei Z Zhang ， Ya-Zhong Chen ,ZheWang.Research on the performance evaluation of government venture capital fund based on factor analysis and DEA model,Journal of Risk Analysis and Crisis Response, 2016, 6 (1) : $15-20$. 